Maynooth Academic Publishing. ISSN 2712-0171.

http://ojs.maynoothuniversity.ie/ojs/index.php/jmhds

\title{
Is the Irish Defence Forces Developing the Necessary Capability to Meet the Operational Requirements of its UN CIMIC Roles? A Case Study of CIMIC Operations in Lebanon.
}

\section{Rory Esler}

This article examines the Irish Defence Forces' (DF) approach to contemporary Civil Military Co-operation (CIMIC) operations in the United Nations Interim Force in Lebanon (UNIFIL), seeking to discover whether or not the DF is developing the necessary capability to meet the operational requirements of its UN CIMIC roles. The paper focuses on the manner in which the DF selects and trains personnel for this operational task, and the degree to which this enables the organisation to meet UN requirements. The article explores international military best practice relating to pre-deployment training and examines Irish policy and practice, presenting the results of interviews conducted with relevant Irish personnel. The research demonstrates that, while there is no doubt that the DF is meeting the operational requirements of its UN CIMIC tasks, this may be the result of its soldiers' collective attitudes and behaviour rather than by design. This suggests that Irish soldiers make good peacekeepers, but that this may not be closely connected to any predeployment training relating to CIMIC.

This article examines the Irish Defence Forces' (DF) approach to contemporary Civil Military Co-operation (CIMIC) operations in the United Nations Interim Force in Lebanon (UNIFIL) mission. It examines how the DF selects and trains personnel for this operational task, in order to discover whether or not the DF is developing the necessary capability to meet the operational requirements of its United Nations (UN) CIMIC roles. With decades of service in country, Irish soldiers have built an enviable reputation as effective peace-keepers in Lebanon. This may reflect the natural ability of Irish soldiers, or it could be a reflection of effective pre-deployment selection and training. If the latter is the case, then there may be lessons here that can be learned to support the development of better practice in Ireland and overseas. If it is the former then it would appear that Irish practice leaves something to chance, and success might not be replicated in missions to areas where the DF cannot rely on informal institutional knowledge gained through decades of prior engagement. Research in this area is significant, as it may offer recommendations to the director of the DF Human Resources Branch and the director of the DF Training Branch that will assist the DF in the selection and training of suitable CIMIC personnel for future UN missions. 
This work has significance beyond the Irish context. Most obviously, of course, it will be relevant for other armed forces interested in addressing predeployment training for CIMIC missions. Soldiers from many countries regularly face the need at adjust to cultural challenges in unfamiliar contexts far from home. Thus, recent experience has led the US military to recognise clearly the importance of predeployment training for all mission types. In campaigns in Iraq and Afghanistan US forces found themselves fighting at a disadvantage due to a lack of cultural awareness in the tactical environment. US military personnel were faced with challenges for which their conventional military training had not prepared them. Military leaders had to quickly move away from the style of war fighting they were well accustomed to, to a more adaptive and distributed decision-making process where the focus of operations was winning the "Hearts and Minds" of the local population (Sepp, 2007). Developing an effective approach to training and selection of military personnel, particularly pre-deployment, can have a direct impact on the success or otherwise of the military mission, regardless of the theatre or type of operations. Research into the efficacy of pre-deployment training for CIMIC missions, thus has relevance across a range of mission types, even if here the focus is on Peace Support Operations.

\section{UN CIMIC requirements}

Peace Support Operations are generally mandated under UN Chapter VI missions. UNIFIL has been described as a "robust Chapter VI" mission by some academics (Bolopion, 2006) or a "Chapter VI plus" mission by others (Marta, 2009). In order to understand the role that a CIMIC team can play within a mission setting, it is important to understand the type of mission such teams are operating within. Chapter VI missions are generally deployed with the consent of the host country and troops are deployed in a peace-keeping role. Chapter VII missions are not necessarily deployed with the consent of the host country and troops are deployed in a peaceenforcement role (un.org, 2018). In a Chapter VI mission, like UNIFIL, the CIMIC team has more freedom of movement than it would in a Chapter VII mission, as the threat level is assessed to be lower. This allows a lot more freedom of action for teams and facilitates Key Leader Engagement and access to more senior members of the local population.

In the context of this research, the main focus will be on UN CIMIC. To have a better understanding of the subject however, it is prudent to describe North Atlantic Treaty Organisation (NATO) CIMIC practices, as they differ significantly from UN CIMIC practices. Holshek (2013) describes NATO CIMIC as a "command and control function used to assist and serve the military commander, executing military tasks to achieve military objectives" (peaceopstraining.org, 2013). Toonen's (2017) definition, in line with that of the NATO CIMIC Centre of Excellence, is "a joint function comprising a set of capabilities integral to supporting the achievement of mission objectives". The focus therefore of NATO CIMIC, as identified in these sources, is on achieving the military mission. De Coning (2005) posits that this 
approach to CIMIC operations works well in NATO, European Force or coalition type operations, where the deployed force is operating in a Peace Enforcement role within a contested environment where there is evidence of resistance to the peace agreement. This type of environment has a significant impact on civil-military cooperation as it reduces the opportunity for teams to operate freely within the geographic area which, by consequence, may reduce the scope for face-to-face meetings with key local leaders.

As most UN missions are mandated to manage peace building in a postconflict zone, through transitions that occur in several phases (De Coning, 2005), UN CIMIC activity is less mission-focused and more focused on relationship building and so requires a different approach than that of NATO CIMIC. Miler (2012) reports how UN CIMIC units help to develop a positive image of soldiers and help establish good relations with local governments and the wider population. This approach to CIMIC operations is therefore very relevant to current DF deployments and particularly to the DF's main troop contributing missions in Lebanon (UNIFIL) and the United Nations Disengagement Observer Force (UNDOF) on the Golan Heights. In these environments, a motivated CIMIC team can achieve a lot with very limited financial and human resources. Relationships that are established between individuals may impact positively or negatively on the perception of the whole force within the area of operations.

As well as being appropriately motivated, CIMIC operators should ideally display favourable attributes that suggest they are suitable for CIMIC appointments. Longhurst (2007:56) describes the attributes of a good CIMIC operator and includes; "honesty, ethical behaviour, responsibility, maturity, resourcefulness, knowledge of military and civilian policy and procedures and decisiveness". Some of these attributes can be achieved as a result of training but others are more intangible and are either present or not in the individual. Either way, selection and training of individuals is key to successful CIMIC operations. Thynne and Cherne (2016) present examples of lessons learned in both UN and NATO CIMIC operations in varying theatres such as the Balkans, Africa, Afghanistan and Iraq. In every instance, the importance of CIMIC preparation pre-deployment is highlighted as a necessary step in achieving the goals of the CIMIC team in the complex, contemporary environment of peace support and stability operations. Furthermore, the importance of the appropriate pre-deployment education and training for CIMIC teams in peace operations is developed to achieve efficiency gains and enhanced overall mission effectiveness.

\section{CIMIC in UNIFIL}

There have been significant CIMIC developments in UNIFIL in recent years. As recently as May 2018, the UNFIL Head of Mission and Force Commander, Irish Major General Michael Beary, opened the third Lebanese Armed Forces (LAF) CIMIC Centre in Southern Lebanon. Major Gen Beary stated that the event "marked the achievement of UNIFIL's initial objective of enhancing UNIFIL's CIMIC partnership 
with LAF" and described the event as a "new chapter" for LAF's CIMIC activities in Southern Lebanon (peacekeeping.un.org, 2018). This clearly identifies an appetite at the operational and strategic level to shape operational activity in South Lebanon by enhancing the relationship between UNIFIL, LAF and civilian agencies within the area. This relationship shaping can predominately be done by CIMIC and civil affairs teams at the tactical level, within each nation's area of operation. This paper aims to develop a clear understanding of the DF's approach to contemporary CIMIC operations in UNIFIL.

\section{PART ONE. Literature review}

Since the UN has only fully embraced the importance of the CIMIC cell in recent years, much of the published literature specific to UN CIMIC is relatively recent. This research considers the broader aspects of selection and training of these personnel and thus explores a wider range of published literature specific to military selection and training.

\section{Cultural training}

Hajjar (2010) posits that of the many important facets of an effective CIMIC team, developing cross-cultural competence - encompassing elements like language proficiency, gender awareness and cultural sensitivity - is now recognised as necessary to be effective in cross-cultural contexts. The author takes a broad approach to the area of cross-cultural training but clearly identifies the elements required to develop an effective team. Hajjar's approach displays a requirement for an extended training period in order to develop a proficiency in the area.

Holmes-Eber, Tarzi \& Maki (2016) describe how the US military has recently focused much attention and financial resourcing on developing this new skill set of cross-cultural competence for its military service members as a result of recent struggles US military personnel have experienced in counterinsurgency and other irregular warfare environments. These authors' area of research is based on a more specific theatre of operations and therefore may reflect theatre-specific recommendations relevant to counterinsurgency operations. While many referenced authors concentrate their research on US-specific theatres of operation, Hajjar takes a more holistic approach and applies his research to a more western-focused audience rather than focusing on US military experiences alone.

Military forces are generally time restrained when preparing to operate in foreign countries and thus take a limited approach to theatre-specific predeployment training. Such training is designed to offer context for the deploying soldier of the theatre they are deploying to but provides limited information about the country and culture concerned. Selmeski (2006:4) describes how this approach to cultural awareness training can generate positive results by "facilitating mission accomplishment and reducing suffering, injury and death" but further contends how "such efforts are generally narrow, superficial, short-term responses to pressing needs". The author argues that cross cultural competence is more about 
understanding how a specific culture acts and thinks, rather than simply understanding how they are governed and their linguistic traditions. OtwinowskaKasztelanic (2011) on the other hand questions whether culture should be taught at all, looking at the subject from the perspective of what is to be taught, from whose perspective and the avoidance of stereotyping in this regard. The author further investigates the idea of developing a sociocultural competence as a means to communicate appropriately, situationally and culturally with due regard to customs, beliefs and principles of a given society.

In the context of this research and the operations of an Irish CIMIC team deployed in a theatre like southern Lebanon, Selmeski's comments are relevant to developing the relationships necessary for the team to operate effectively. Simple behavioural actions, displaying sensitivity to religion and local culture, can be incorporated into everyday interactions between military CIMIC teams and the local population to display an understanding of local culture and therefore enhance the relationship between the military and civilian population.

\section{Language training}

Knowledge of the local language is of vital importance for all military personnel operating in foreign environments. On most overseas deployments, members of the DF who have cause to interact with the local population on a regular basis have, at best, limited access to authorised language assistants or interpreters. The availability of these locally employed civilians is not guaranteed and is generally on a first-comefirst-served basis. As a result of this, there are regularly occasions when members of the DF must communicate non-verbally with the local population. This situation is not ideal, particularly where tensions are running high. Having access to personnel within the deployed military force who possess the requisite language skills is invaluable. Asch and Winkler (2013) describe how language skills play a vital role in the national security infrastructure of the US. Language skills are varied throughout the US intelligence community with members of the military, government civilians and contracted professionals offering varying levels of proficiency in the specified language at home and on overseas deployments. These authors contend that on certain military missions, particularly in the Middle East, having knowledge of "colloquial phrases and syntax" can change the context and thus the outcome of the conversation. In this case and in line with the views of these authors, having native speakers providing interpretation or training to soldiers is the best solution.

The DF currently do not provide any military language assistants on overseas deployments. Further research will determine if this is due to the non-availability of adequately trained personnel or the fact that the DF have not identified this as an area of requirement for deployed forces. Having this capability available within the unit resources would provide a significant benefit to any deployed unit. 


\section{Negotiation training}

The role of the CIMIC operator is complex. The team leader's activities will be made up of "co-ordination, co-operation, mutual support, coherent joint planning and information sharing" (CIMIC field handbook, 2014:23). The team leader must present as personable, be a good communicator, display empathy and be respectful of the person they are interacting with and of their culture. In effect, the CIMIC team leader must be a good negotiator. Fisher \& Ury (1981:xviii) highlight the importance of negotiation training for everyday interactions and state that "everyone negotiates something every day". In much the same way, every interaction between a CIMIC team and any local or key leader is, first and foremost, a negotiation. Thompson (2012:24) describes negotiations as "an interpersonal decision-making process" which must be utilised when there are constraints on a situation, i.e. when everyone cannot get everything they want. This has relevance to the CIMIC team member trying to balance finite resources between competing local interests. This paper will determine the extent of negotiation training available to DF CIMIC team members pre and during deployment.

\section{CIMIC teams and NGOs}

The role of the CIMIC team on operational deployments has developed considerably in recent years. The type of work now undertaken by these teams was traditionally performed by dedicated humanitarian teams, Non-Governmental Organisations (NGOs) or specifically-trained civilian organisations. Since the end of the Cold War, these lines have become somewhat blurred as military operators are often more suited - and certainly more favourably located geographically - to undertake the role. Gourlay (1999:33) comments how military and humanitarian organisations share common roots in war and she further develops this position by noting that "modern day humanitarian was actually founded on the battlefield". Gourlay references organisations like the International Committee of the Red Cross, Oxfam, CARE and the Save the Children Fund to expound the link between humanitarian organisations and their role in hostile environments. Slim, (1996:124) notes that "for the last 100 years, militarism and humanitarianism have represented two sides of the same coin - humankind's inability to manage conflict peacefully". Slim's approach suggests the inability of one side alone having the capabilities to conduct both humanitarian and military roles effectively. This approach further suggests that in order to be effective in such an environment, a civilian team would require appropriate military training, or the military team would require appropriate humanitarian training. Both authors, however, clearly identify the close connection that traditionally existed between military and civilian actors in theatres of conflict or post conflict.

Gourlay (1999:36) is somewhat more critical of the motivational factors driving military participation in construction or repair projects, when she suggests such projects are "essentially public relations exercises designed to reap hearts and minds returns, to further a security objective". Gourlay identifies how the military's 
"short-term, non-participatory approach" can be a source of tension between military and civilian organisations deployed within the same theatre as the objectives of each organisation are vastly different. This approach relates to this research as the existence of a CIMIC team within a theatre may reduce the need for civilian humanitarian operators to be co-located. This highlights the requirement for military organisations to select and train CIMIC teams appropriately and thus reduce the need for civilian operators to be co-located with military teams on military missions.

\section{Sociodemographic factors}

The effects of sociodemographic factors such as age, gender, education and previous experience or overseas employment may be useful as a predictor of cross-cultural attitudes and developed skills of individuals. The individual's appreciation of the importance of cultural awareness may impact on how they interact with the civilian populations. Military rank, which is generally linked to the individual's age and experience, may also impact on their approach.

Watkins \& Sherk (2008) discuss a US military recruiting phenomenon which highlights the effects of sociodemographic factors on military recruitment. This phenomenon is known as the "Southern military tradition" where the Southern states are well known for their higher numbers of military recruits. Research conducted by the US Office of the Under-Secretary of Defence in 2016 shows the over-representation of Southerners in the US military. The authors link these higher levels of recruitment to sociodemographic factors such as age, education, religion and military tradition within families.

Regardless of the focus of the above research being on US military personnel, the same sociodemographic factors mentioned here may also influence recruitment figures in the Irish DF. Age, education and family links to the military have an influence on decisions to enter the Irish military and furthermore the path of entry, whether it will be apprentice, recruit, cadet or direct entry. This is manifested in many families having strong military traditions in the DF. This may further have an impact on the individual's willingness or desire to deploy overseas and the type of role they would aspire to fill once deployed.

Holmes-Eber, Tarzi \& Maki (2016) look at the impact of the factors mentioned above and posit how an individual's background will have an influence on how they act or react in the future. These authors further suggest that individuals that grew up in a multi-cultural environment will adapt to a multi-cultural environment much quicker than those who have not. Factors such as regular interactions with civilian populations during previous overseas deployments or exposure to foreign cultures in a non-military environment will also develop cultural maturity. Having an awareness of the background of soldiers can be useful when deciding how best to deploy them and may have a direct impact in the context of this research. Soldiers with multicultural backgrounds or experience with more than their own cultural background may be good candidates for CIMIC roles. Again, the views of these authors are 
focused on research of the US military, where cultural diversity is more commonplace than it is for the Irish DF. However, the influence of culturally-diverse backgrounds of Irish soldiers must be considered to be a developing area.

\section{Cultural awareness}

For those individuals who have never experienced a multi-cultural environment or who were brought up in a non-diverse cultural environment, formal training in cultural awareness can prove beneficial to the individual and to the organisation. Training pitched at the correct level and delivered by appropriate personnel preferably by those of a different cultural background - can be as beneficial as time spent on deployment and give the individual something to build their experiences on. Greene-Sands (2014) argues how having an understanding of the operational environment through cultural awareness competencies supports the Commander's decision-making process and assists in the Comprehensive Operations Planning Directive process. The US Marine Corps has recently established the Centre for Advanced Operational Culture Learning to provide cultural training to all soldiers prior to deployment, such is the perceived value of cultural awareness to deployed personnel. While cultural training is provided for all deploying personnel, individual experts are identified, both officers and NCOs, and further focused training is provided for these personnel. This approach is also evident within the Irish DF, albeit on a significantly reduced scale.

Greene-Sands (2014) further expounds how the US Marine Corps has added a planning tool to consider the civil population when planning military operations. This Green Cell is utilised to establish the impact of local cultural activity on the military operation and is conducted in much the same way that military Intelligence staff conduct the Intelligence Preparation of the Battlespace with the focus being on the civil dimension and the impact of cultural norms rather than on an enemy. This approach displays a willingness to understand the operating environment from the point of view of both the military and the local population. The practice of using the Green Cell is also commonly utilised in NATO's pre-deployment training - a fact that clearly suggests that such a practice is useful and of benefit in the preparation and pre-deployment phase.

On the other hand, Reyskens \& Resteigne (2015:217) argue that having an awareness of cultural norms alone is not sufficient. While this does not discount Green-Sands' (2014) approach, it suggests that their approach does not display cognisance of the full operating picture. The authors contend that a reaction to cultural diversity cannot be defined before an interaction takes place as "responding to cultural diversity entails changing definitions and guidelines". The authors further contend that an understanding of culture is based on the individual's own perceptions and beliefs and therefore the response to any given situation will be different depending on the individual and their understanding of that situation. This may present a challenge for a military organisation whose mission depends on defined outcomes. The most practical solution for a military organisation, therefore, 
is to provide sufficient training to personnel who will have interactions with the local population and try to mitigate individual human error wherever possible through focused selection and training of personnel.

\section{Gender balance}

Crawford, Lebovic \& Macdonald (2015) discuss the importance of gender balance on operational deployments in a UN context. The authors explain that, since 2004, the UN has sought to increase the numbers of females deployed with UN peace keeping operations with varying levels of success, generally dependant on individual troop contributing countries' ratio of female members. The initial reasons, as outlined by these authors, for the UN's increased representation of female staff was to address concerns from contributing nations about the absence of females from negotiations and decision-making roles in post-conflict environments. The absence of females in these situations is described by the authors as having had a negative impact on the outcome of such interactions. Looking at this example simplistically may suggest that the inclusion of additional female personnel on a CIMIC team would have a positive impact.

The approach to gender balance from a CIMIC team point of view is essential. Depending on the mission area, female CIMIC operators may be received differently. In some predominantly Muslim countries, females do not enjoy the same freedoms as males and this acceptance of social class differentiation is part of the local cultural norm. This social-cognitive domain theory is described in greater detail by Verkuyten \& Slooter (2008) where recent studies found Muslim adolescent females to be more in favour of Muslim minority rights than their non-Muslim counterparts. Research in this area is underdeveloped and, as a result, it is limited. The focus of gender balance in this research therefore will be on the inclusion of female CIMIC operators and the impact this has on CIMIC operations in UNIFIL.

Karim \& Beardsley (2013) assess the impact of UN Security Council Resolution 1325 , which acknowledges the disproportionate and unique impact of armed conflict on women and girls by "urging troop contributing countries to increase the participation of women and incorporate gender perspective in all UN peace and security efforts" (un.org 2019). The authors explore the question of whether female soldiers are sent to areas where they are most needed, i.e. where sexual violence and gender inequality have been most prominent, or if they are sent to areas with the greatest gender imbalance from a national troop contributing perspective. The authors further define the issues with this approach to gender balance in UNPKOs, with negative outcomes due to a lack of planning and the paying of lip service to an identified gender imbalance issue. The inclusion of female soldiers on CIMIC teams simply to achieve gender balance can have a profoundly negative effect on the team, if the female concerned is not suitable for such a role. Regardless of gender, members of CIMIC teams must have the right aptitude for the role. There was also a concern regarding the increased use of sexual violence against vulnerable people in conflict zones, coupled with numerous reports of sexual offences allegedly committed by 
male UN personnel deployed in conflict and post-conflict zones. Whalan (2017) develops this point with reference to the June 2017 case of the removal of an entire peace-keeping force from the Central African Republic over sexual abuse allegations. Increased numbers of female participants on UN peace keeping operations and on CIMIC teams may therefore have an effect on how the team conducts itself, the outcome of engagements and the general perception of the peace-keeping force.

\section{Importance of CIMIC operations}

Although predominantly NATO CIMIC focused, Rehse (2005) refers to CIMIC as a controversial term that has often led to heated debate between the civilian, military and humanitarian actors involved in the process. He further develops the issues concerned where military actors are confronted with situations that are not traditionally military in nature but, nonetheless, need to be dealt with by military actors. Sepp (2007:219) develops this point further, describing military support as essential, as militaries are the only agencies with the "material resources, numbers and quality of personnel to implement critical programmes in the austere and hostile environment". In the context of this paper, it is inconsequential whether it is UN or NATO CIMIC that is being discussed. The issues identified by these authors apply equally to CIMIC teams in either environment.

Jenkins (2003) identifies how CIMIC operations are a central activity in peace support operations and have become recognised as such. He further develops this statement by identifying the roles that CIMIC staff are involved in outside traditional military activity, such as interacting with international groups who are providing humanitarian assistance and creating stability. Added to these roles, Jenkins (2003) outlines the importance of timely reporting of such developments and the responsibility that CIMIC teams have in this regard. According to Jenkins therefore, the role of the CIMIC team should be viewed as part of the bigger picture and the overall creation of a stable environment. The development of such an environment with solid foundations will create the conditions required to build economic and social stability. These tasks undoubtedly go beyond the perceived scope of a nonspecialised CIMIC team, as is the case with some military CIMIC teams deployed. Jenkins' (2003) research in this area is relevant to the Irish DF with regard to how CIMIC personnel are selected and trained for these challenging roles. His research suggests that certain personality types are more suited to CIMIC roles, given the demands of the team acting in an almost diplomatic way on occasion. His proposition that the CIMIC teams are part of the effort required to create a stable environment, built on solid foundations and social stability, may even suggest that a good CIMIC team could be considered to be the Centre of Gravity of the mission. This approach further verifies the importance of the selection and training phases for CIMIC team operators.

It is clear from research in this area that a formalised approach to CIMIC operations is a relatively new concept in global peace-keeping. It was not until 2001 that the NATO CIMIC Centre of Excellence, or CCOE as it is known today, was 
established in The Hague (cimic-coe.org, 2018). The following year, in September 2002, the UN Department of Peace Keeping Operations issued its CIMIC policy to offer structure to a concept that had been embraced ad-hoc for a number of years. This policy has been updated on a number of occasions since 2002, most recently in 2010. The way in which CIMIC operations are conducted within any mission framework will have an effect on the mission. This paper assesses how effective predeployment selection and training of personnel for CIMIC roles in operational environments will have an impact on the effectiveness and the influence that CIMIC activity can have on military operations.

The above review of relevant published literature suggests the areas considered important for soldiers to train for prior to deployment on military operations. The area of culture awareness training seems to take considerable precedence over any other area of training, regardless of the location of the military mission or the nations involved. Recruitment and selection within military organisations also displays strong links to sociodemographic factors such as age, gender and education and suggests that these factors can directly influence an individual's decision to join a military organisation, to volunteer for overseas service and also can affect their interactions with other people. This factor is more relevant when the area of selection for CIMIC appointments is considered.

\section{PART TWO. Research methodology}

Research undertaken to support this paper was inductive, as it was intended to elaborate on an area of research that was already familiar to a certain cohort within the DF and military organisations in general, as opposed to testing a new hypothesis. Utilising qualitative research provides a deeper understanding of the subject matter as it pertains to Irish soldiers. Wolcott (2001) recognises the connection between researchers and participants of research in post-positive research. Therefore, reflections and experiences of the interviewees has facilitated the development of the findings of this paper.

Primary data was collected through semi-structured interviews with selected Irish and Finnish military officers who have been previously employed as CIMIC officers in UNIFIL. Elite interviews were also conducted with training staff in the United Nations Training School Ireland (UNTSI) to glean information on UN training practices pre-deployment and with the DF Human Resources function to gather information on overseas selection procedures for officers. The collected data was based on observed phenomena through the personal experiences of the interviewees. Interview questions were constructed to ensure they were kept objective and focused on fact, rather than allowing the interview to be dominated by subjective viewpoints. This approach facilitated the emergence of empirical evidence.

As a starting point to gathering the required data, analysis of Irish CIMIC documentation was conducted in UNTSI. This analysis of documentation was used to 
evaluate the current practices of training specific to CIMIC roles on UN missions and as cross-verification of data to facilitate improvement of objectivity. UNTSI is currently responsible for all UN focused training for soldiers and selected civilians' pre-deployment and currently runs an Overseas Qualification Course three times per year. In addition to this, the school also runs an international CIMIC course once per year and this course is open to Irish and foreign soldiers and civilian participants, drawn usually from NGOs and other such organisations. The international approach to this course, along with the joint co-operation with external agencies such as the NATO CIMIC Centre of Excellence, and the Finnish Defence Forces International Centre, which is an internationally recognised crisis management education and training centre, ensures CIMIC training in UNTSI is linked to the operational picture and reflective of international best practice.

Closed fixed response interviews, where the interviewee would be restricted to answer based on the most appropriate response, was not deemed suitable in this case. Non-structured interviews were also considered but due to the subjective nature of responses from these interviews, they were discounted. Similarly, focus groups were considered but discounted as these interactions tend to move towards a consensus regardless of an individual's opinion or experience. Bloor (2001:20), describes how differentials between participants in a focus group "may cause some views to be silenced, for example, groups where individuals vary in status and in power". Due to the nature of the military rank structure, this was deemed an unsuitable method of collecting data.

Semi-structured interviews were considered the most suitable technique for data collection in this research. Questions were developed based on lessons learned from published literature, personal experiences and document analysis. Questions were structured in such a way as to allow for free-flowing answers, whilst ensuring that the same general areas of information were collected from each interviewee. Longhurst (2003:143) describes how semi-structured interviews "unfold in a conversational manner offering participants the chance to explore issues they feel are important".

Creswell (1998) recommends that all information collected during an interview process should be consolidated and re-examined in order to better understand the data as a whole. This process was undertaken to formulate common themes through the various interviews to produce a measurable data set. The common themes identified were in the areas of selection for overseas appointments; pre-deployment mission-specific training; and the perception of the CIMIC team in the operational environment and CIMIC doctrine. The identification of common themes allows for cross referencing with the published literature in this field to develop conclusions and identify potential gaps in knowledge. Antonesa et al. (2006:89) posit that "post-positivists are agreed on the need to analyse data and to theorise on the findings", but these authors continue to the conclusion that "there is no prescribed analytical method in most post-positivist approaches". Analysis of the 
data collected was therefore used to develop a reflective picture of selection and training methods used in the Irish DF for CIMIC personnel, as recounted by those directly involved in the process.

All personnel selected to participate in the interview process had direct experience of filling the appointment of CIMIC officer in UNIFIL within the last nine years. The fact that each individual interviewed had different experiences to recount added to the depth of information and thematic development. Antonesa et al. (2006) reminds us that the interviewee should be informed if the focus of the interview changes and the participant finds themselves discussing issues outside the scope of the interview. This approach was adopted throughout the course of all interviews. Use of a single primary data collection process through semi-structured interviews could lead to limitations, however, this was mitigated through the collection of secondary data through CIMIC documentary analysis.

\section{PART THREE. Research findings}

The direction of this research was guided by the broad themes that emerged during review of existing literature. A number of the themes that evolved during this process were focused on during the semi-structured interviews to gain a better understanding of how the DF prepares to meet the requirements of UN CIMIC roles in theatre. The main themes identified were how the DF selects and trains personnel to fill these roles pre-deployment and the importance of training in areas such as cultural awareness, negotiation training and language proficiency on overseas deployments. Gender awareness was also highlighted as an area of interest. Sutton and Austin (2015) discuss the importance of being true to the participants in qualitative research and the process of using the grounded theory approach to research of this kind. This approach facilitated the emergence of valuable insights into the professional and personal experiences of those interviewed.

In total, eight semi-structured interviews were conducted. Six of these interviews were conducted with officers with recent direct experience as CIMIC officers on UN missions. Four of these officers were Irish and two were Finnish. For participant confidentiality purposes, the Irish officers have been designated IO1, IO2, $\mathrm{IO} 3$ and 104 . The Finnish officers are designated FO1 and FO2. While the main focus of the research was on these six officers who had a combined total of five years' direct experience as CIMIC officers on recent UN deployments, research was also conducted into how the DF selects and trains officers for such appointments. From a selection perspective, the officer responsible for selection of officers overseas, Comdt. R. Carberry was interviewed. This elite interview was conducted in DF HQ. To glean an insight into training of UN CIMIC personnel, a second elite interview was conducted with the officer commanding UNTSI, Lt. Col. T. O'Brien.

\section{Selection for CIMIC appointments}

The process for selection for overseas service for DF officers, as detailed by Carberry (2019), is a complex but fair system which takes a number of factors into 
consideration. Various measurable elements are considered before an individual is selected for overseas deployment in order to maintain a fair and equitable system in an organisation of over 1,100 officers. In relation to CIMIC appointments specifically, Carberry (2019) said;

Only officers who meet the rank criteria and who have completed the tactical CIMIC course can be selected for a CIMIC appointment overseas.

While this is a pre-requisite for selection for CIMIC appointments, selection procedures in line with DF regulations are the remit of the incumbent selection authority. While Carberry (2019) acknowledged that there may have been cases in the past where officers did not fully meet the selection criteria for this appointment, he clarified that this has not been the case during his tenure. Referencing the UN's selection requirements for CIMIC appointments, Carberry (2019) stated;

Once there is an essential qualification associated with an appointment, if an individual doesn't have that qualification, they are not considered for that appointment.

Considering O'Brien's (2019) point that “[The DF] have mandatory UN deployment material for all personnel and specific material for CIMIC personnel provided by the UN", there is a direct correlation between what the UN require from an individual selected to do a CIMIC job on a UN deployment and how the DF selects personnel for these roles.

Considering gender balance on CIMIC teams, with reference to Hajjar (2010) and his identification of gender awareness as an important facet of an effective CIMIC team, the issue of selection of female officers specifically was explored. While the UN selection criteria makes explicit reference to "female applicants [being] strongly encouraged" for Military Staff Officers and United Nations Military Observers, there is no such criteria associated with UN CIMIC appointments in general. Crawford, Lebovic \& Macdonald (2015) discuss the UN's attempts to increase female participation on UN missions since it was first identified as an area of interest in 2004. According to Carberry (2019), the UN now seek to increase this level of female participation to $16 \%$ with aspirations to achieve $25 \%$ female participation by 2025 . For the DF, this would mean that of the approximately 40 Military Staff Officer and UN Military Observer appointments currently deployed, 10 female officers should be "strongly encouraged" to fill these appointments with no consideration towards female CIMIC officers. As stated by Holmes-Eber, Tarzi \& Maki (2016), other major military forces around the globe are now investing considerable resources into areas including gender awareness and balance as it is identified as a contributory factor in a specific skill set. The UN's approach in this particular area appears to be lacking any direct guidance on the selection of females in CIMIC appointments.

A number of other soft skills were identified as desirable in CIMIC team members during literature review. Skills such as language proficiency, cultural awareness and negotiation skills were again specified by Hajjar (2010) as important 
facets. Asch and Winkler (2013) define clear links between language proficiency and the vital role it plays in the security infrastructure in the US. However, as identified earlier and referenced throughout the interview process, the Irish DF relies almost completely on local civilian language assistants to communicate with the local population in Lebanon. Although these civilian employees are security vetted by the UN, it is difficult for an Irish soldier to assess if the language assistant is translating exactly what is being said or if there is any personal interpretation of what is being communicated. If an individual has a proficiency in a foreign language, e.g. Arabic, this skill is not captured by the DF HR system unless volunteered by the individual. Likewise, the negotiating skills of an individual - as described by Thompson (2012) as "an interpersonal decision-making process which must be utilised when there are constraints on a situation" - are not formally recorded unless that individual has qualified on a DF approved course or has offered the information for inclusion on their personal file. As stated by Carberry (2019);

The capturing of this information is more difficult. The system is only as good as the information that is submitted into it. You cannot search for information that is not on the system. The individual must be willing to share the information in the first place.

Even if the information of a personal qualification has been submitted for inclusion on an individual's personal file, there is no formal recognition for the qualification unless it is specified as a pre-requisite for the appointment. However, common sense prevails where appropriate, as detailed by Carberry (2019);

As per regulation, there is no recognition of these types of qualifications. However, if I had two recommended applicants and they both met the prerequisite qualifications for an appointment and I knew one of them to have Arabic fluency or a Masters in International Relations, I would give that person greater consideration for a suitable appointment. There is nothing laid down in the regulations to support that. It is down to the ethos of the selection authority at the time of selection. Best fit for jobs will be considered.

A CIMIC team deployed to any UN mission is essentially a tactical CIMIC team as they are deployed at the tactical level following the orders of the Battalion Commander. The function of the tactical CIMIC team forms part of the larger civilmilitary focus at the operational level of the mission and thus feeds into the bigger picture. The CIMIC team therefore should not be seen as working in isolation, in much the same way that the manoeuvre element does not operate in isolation.

UNTSI run an International CIMIC course once per year. This course is based on NATO CIMIC doctrine but the focus of the tactical CIMIC training is on the CIMIC function in UNIFIL. For a broader understanding of CIMIC at the operational level, UNTSI has strong connections with international CIMIC training facilities in Europe to further develop the skill. O'Brien (2019) develops this point further; 
We do not have a stand-alone tactical CIMIC course. We have to access to, and we have offered this to [the selection authority], if personnel are selected in advance, we can send them to Europe, to the NATO school or to the NATO CIMIC centre in Germany and they can either do a one-week or a two-week CIMIC course. If they are already qualified, they can go on a two-week exercise which is held every November in Germany.

Evidently, strong links exist between UNTSI and international CIMIC centres of training to ensure CIMIC training is in line with international best practice. However, the selection of CIMIC personnel to fill appointments on UN deployments may not be prioritised at times as described by O'Brien (2019);

We offered [international CIMIC training] to the most recent UNIFIL Battalion, but the CIMIC team hadn't been selected yet. We will offer it again to the [next] UNIFIL Battalion which will deploy in November [2019] and if their Unit Commander is interested, we will try and make it an ongoing unit SOP that every UNIFIL rotation will send two people to Germany to take part in the biggest CIMIC exercise that is held in NATO. That is how we train and facilitate training of personnel.

As detailed by O'Brien (2019), a one or two-week long tactical CIMIC course is available in Germany to qualify personnel to fill tactical CIMIC appointments. The international CIMIC course run in UNTSI annually requires significant planning and preparation due to the participation of international personnel and civilians. The above mentioned CIMIC training is of course merely complementary to the CIMIC training in UNTSI. Although there is no stand-alone tactical CIMIC course, the International CIMIC course qualifies Irish personnel to fill CIMIC appointments on all missions as detailed by O'Brien (2019);

We will generally have a previous experience brief on the course from one of the African missions, tChad for example and from a UN mission so we get a good mix of experience. We also run a three-day exercise on that two-week course and the exercise is a number of serials based around UNIFIL CIMIC-type scenarios. By completing that exercise, you qualify in the DF to serve in a CIMIC appointment.

Scenario-based training using serials reflective of potential real-life incidents can be the most effective method of conducting training in time-restrained situations. Selmeski (2006) posits how this type of training facilitates mission accomplishment and offers context to the soldier about the situation to which they are deploying. Applying this method of training to CIMIC serials will ensure maximum learning for troops in a short training period. However, addressing all possible scenarios in a short time frame is not feasible, as each interaction a tactical CIMIC team has with any member of the local population is unique. Role-players used in these scenarios should also be ethnically matched to the area of operation where 
possible. In this case, Lebanese males or males with Arabian heritage would add to the realism of scenario-based training.

There is no formal CIMIC-specific training for troops on the UNIFIL predeployment training syllabus. The assumption is that any personnel selected for a CIMIC appointment will already be trained and qualified in line with what is mentioned previously. There is no formal allocation of CIMIC training either on the Overseas Qualification Course. Previous experience briefs will be offered to deploying CIMIC teams from previous CIMIC officers at the discretion of the training staff and subject to availability of suitably qualified personnel. Cultural awareness lectures are also included on the training syllabus and are delivered by a Lebanese native when available. However, there is no formal Lessons Learned process or AfterAction Review procedure for previous CIMIC officers. This is detailed by O'Brien (2019);

There is no formal procedure. Debriefs of returning units has not happened in a generation. There is no formalised method of doing it. We do bring in returning officers to brief the next unit regularly however.

UNTSI receive the monthly briefs from deployed units to keep abreast of the developing CIMIC landscape and changing requirements and the school develops CIMIC training in line with it as required. O'Brien (2019) develops this point;

We keep up-to-date from the [UNIFIL] monthly reports. If something new is encountered, it is integrated into the training block. There would be great benefit to a formal process for capturing these lessons.

As detailed during the course of this interview, new information regarding the changing environment in Lebanon is captured formally on 12 occasions during the year. However, implementing changes in the training of personnel is only done at the initiative of the staff in the training school. A formal After-Action Review with returning personnel should be conducted twice per year and a formal review of training processes should be conducted directly after these reviews to compliment the training of personnel in line with changing requirements.

In relation to language and negotiation training, O'Brien (2019) suggests looking beyond our inherent skills within the Permanent Defence Forces and utilising the skills available within the Reserve Defence Forces (RDF). UNTSI currently utilise the skills of serving RDF personnel to develop both areas. This is, however, done on the initiative of the staff in UNSTI rather than through a formal approach. He further discussed the challenges of incorporating additional training into an already full predeployment training syllabus. On both matters, O'Brien (2019) suggests that these areas should be part of lifelong learning within the DF in order to see any tangible returns. Asch and Winkler (2013) discuss how an understanding of colloquial phrases and syntax can change the context and thus the outcome of a conversation. This level of knowledge and understanding of a local dialect may only be achievable through imbedded learning, i.e. deploying personnel on UN missions solely to learn the local 
language. The DF has been operating in Lebanon since 1958 and still relies on local language assistants to communicate with the locals. Interestingly, many of the locals now speak English with regional Irish accents.

\section{CIMIC - A national perspective}

The following is primarily focused on the experiences of the Irish CIMIC officers interviewed. During the course of interviews, discussion was allowed to progress in order to develop a better understanding of personal experiences both pre and postdeployment. The experiences of the Finnish officers interviewed will be used as balance and for comparison where necessary.

The effects of sociodemographic factors, including previous professional and personal experiences as a predicator of potential future appointments, were discussed previously. Watkins \& Sherk (2008) discuss the impact sociodemographic factors have on recruitment in the US military and draw links between these factors and the type of employment with which such individuals will naturally converge. This research is backed up by Holmes-Eber, Tarzi \& Maki (2016) where their focus is the correlation between past experiences and future reactions to particular experiences. However, no such links were observed between those interviewed, the appointments they filled at home or on previous missions overseas and their selection as CIMIC officers on UN missions.

The range of appointments previously held while in Ireland varied greatly and included appointments in logistics, procurement, training, operations, administration and even policing roles. Although this is a varied selection of previous experience, none of these roles would necessarily indicate suitability to fill a tactical CIMIC appointment. From an overseas deployment perspective, two of the Irish interviewees were on their first overseas deployment when selected to fill CIMIC roles. The other two officers had filled appointments in transport, administration and operations-type roles in Lebanon and Bosnia. The Finnish officers had similar experiences in home appointments and neither had previous overseas experiences. It is evident therefore from this selection of interviewees that previous experiences were not utilised as an indicator when selecting officers to fill CIMIC appointments.

As mentioned above, many appointments on an overseas deployment require some form of pre-deployment training or qualification as mandatory preselection criteria. Carberry (2019) referenced the mandatory selection criteria for CIMIC officers as meeting the rank criteria and the successful completion of a tactical CIMIC course. However, two of the Irish officers selected to fill CIMIC appointments in UNIFIL had not completed any CIMIC training and furthermore had "little or no understanding" of what was involved. $\mathrm{IO} 1$ recalled being selected for a CIMIC role;

I had no understanding of what was involved in a CIMIC role. I had a basic understanding on what was involved from the title of civil military coordination. I probably had my own pre-conceived ideas what was involved 
from a liaison with civilian's point of view. As I got into it, I knew there was a bit more involved and researched the role myself.

IO2 had a similar experience and recalled being selected for the appointment;

I had not completed a CIMIC course, so my knowledge of the role was limited. I spoke to a few officers who had undergone a CIMIC course and worked in CIMIC appointments overseas and they provided information on the role and responsibilities required. I read as much as possible and contacted the CIMIC officer in Lebanon as soon as I was selected.

Although these individuals had not received any formal training in CIMIC, they both felt it was necessary to conduct their own research and use initiative to contact other officers who had previously completed the job, with a view to understanding the role better if not the overall concept of CIMIC. 103 and 104 had both completed the International CIMIC Course in UNTSI. However, the motivation explained for completing this course was not specifically to fill a CIMIC role overseas but to increase their chances of being deployed overseas in any role. The fact that the appointment was CIMIC-specific was secondary. Although both officers described the course as beneficial and helpful in achieving "a very broad understanding of CIMIC", additional learning and understanding of the role the CIMIC officer plays in UNIFIL was only achieved through personal initiative by liaising with officers with previous experience in the role. The experience of FO1 and FO2 was similar. Both officers conducted a formal week-long tactical CIMIC training course in the Nordic Defence Co-operation Centre in Denmark pre-deployment and had completed CIMIC serials during their pre-deployment training in Finland. However, direct liaison with previous CIMIC officers - and in this case a week-long recce to Lebanon pre-deployment proved to be of most benefit as recalled by FO1;

This one-week recce to the area was the most useful part of the training because I had the chance to discuss and see what the previous rotation was actually doing.

In all cases, limited CIMIC-specific training was conducted during the predeployment training. CIMIC serials were included in exercises and past experience briefs were incorporated in some cases. All Irish officers interviewed had spent ten days in Finland during the Mission Readiness Exercise pre-deployment and benefited from meeting their Finnish counterparts prior to deploying to the mission area. CIMIC serials were also included in this training period. However, a basic comparative analysis between the experiences of the Finnish and Irish officers pre-deployment suggests that a recce to the mission area in Lebanon, with time spent with the incumbent CIMIC team, achieved a greater understanding of the role of the CIMIC team in theatre and gave a greater understanding of the realistic tactical role of the CIMIC team.

Developing Situational Awareness (SA) prior to deployment to a new area is vital. The overseas operations section, which is a branch of the DF current and future 
operations section, is charged with providing the necessary SA briefs to deploying troops. These briefs usually take the form of current information, political and operations briefs and are provided to ensure all personnel have a basic understanding of the operational environment. Personnel are encouraged to develop their own knowledge of the operational environment through open source material, e.g. newspapers, television and other media streams pre-deployment. All officers and non-commissioned officers receive these briefings in UNTSI during predeployment training. No CIMIC-specific SA briefs are provided pre-deployment, despite the fact that very detailed and up-to-date village files are maintained in theatre by the incumbent CIMIC team, as detailed by IO1;

Nothing specific. Other than the standard briefs that everyone gets on the whole area and the situational awareness briefs, we did not receive CIMICspecific brief.

This point was also backed up by IO2;

To my knowledge we did receive general situational awareness briefings in UNTSI and cultural briefings but not to the level of detail that could have been provided on the villages we would be working in.

In order to develop an up-to-date picture of the villages, the village leaders and ongoing projects that the CIMIC team would be working with, it was necessary for selected CIMIC team members to make informal contact with the deployed CIMIC team in Lebanon. 104 recalled the following;

However, to receive an up-to-date snapshot of current CIMIC activities it was necessary to contact the CIMIC team in theatre. They were very helpful in sending on village assessments, lists of current projects and proposed projects and information on finance streams.

The approach of making direct contact with the currently deployed team in theatre has evidently become the accepted practice for CIMIC personnel predeployment. 103 had a similar experience;

Whilst there was no mandatory direction to make contact with the CIMIC team in theatre, it is unthinkable to imagine that any officers deployed to serve in a CIMIC role in UNIFIL would not make contact with their counterparts to gain some situational awareness of the role they were about to undertake.

Although the processes outlined above are informal and require initiative from the selected personnel, they are nonetheless effective. In all interviews, there was evidence of the lines of communication being opened by the personnel selected to fill CIMIC appointments well in advance of deployment. This is a practical and effective method of collecting primary data on the role about to be undertaken and is encouraged. 
Each interviewee recognised the benefit of language training but similar to the views of O'Brien (2019), considered language training as a longer-term training requirement or part of lifelong learning. 104's view, in line with O'Brien (2019), was that language training should be conducted post-deployment in theatre and should be encouraged, although not uniquely for CIMIC officers. A number of interviewees, (IO1, 103 and FO2) recalled having issues with inaccurate translations being conducted by the local LA, with 101 recounting;

I experienced a few occasions where the local language assistants were not translating the actual conversation. We are totally reliant on them and we are at their mercy.

This is an area for concern for deployed troops. An inaccurate CIMIC patrol report based on an inaccurate translation can lead to an unnecessary escalation of tension which can have an impact on patrol frequency, posture and the overall threat level assessment. Again, all interviewees reported developing very basic Arabic words and phrases shortly after deployment and viewed this as a "nice to have rather than a need to have". As 104 recalls;

As there is a requirement for a language assistant with all interaction with key and local leaders, rudimentary Arabic knowledge is helpful to show an interest in the language of the host country, however I would see this as being of low priority.

The Finnish experience differs slightly for two main reasons. Firstly, they are already operating in a second language as all business in the UN is conducted in either of the UN two official languages, English or French. Secondly, the Finnish military deploy military language assistants (members of the Finnish military who are fluent in Arabic) to UNIFIL and so experience less issues with inaccurate translations.

During his interview, O'Brien (2019) suggested that on each deployment to the Middle East, three personnel should be selected to learn Arabic for the duration of their trip. As learning the language would be their primary responsibility, they would not be tasked with anything that would encroach on this learning. If this approach was to be implemented and formalised, in three to five years, the DF would have a pool of military language assistants to draw from. Arabic language training in Ireland could then be formalised to complement this approach.

Being culturally aware was seen as a key factor for the successful integration of the CIMIC team by all interviewees. Sepp (2007) looks extensively at the problems encountered by the US military in Iraq due to a lack of understanding of cultural norms. This holds true for any predominately western force deploying in the Middle East. IO1 recalls;

You need to be aware of the [cultural] nuances and that goes across the board. A situation can escalate very quickly if it's not handled properly. 
IO3 made the point that cultural awareness must be understood properly and so should only be delivered by a local civilian from the area of deployment. 102 further made the point that the various religious and cultural complexities of the region could not be fully understood until in theatre. FO1 and FO2, who had both received cultural awareness training as part of their pre-deployment training, saw the training only as a good starting point from which to develop a proper understanding of cultural norms post deployment. It is clear that there is an importance associated with cultural awareness training pre-deployment both in Ireland and Finland. However, only an appreciation of culture can be taught to an individual. As outlined by Hajjar (2010) and Holmes-Eber, Tarzi \& Maki (2016), cultural awareness is a skill. Some people can adapt to a skill set better than others and so it is likely that this skill can only be properly developed by experience. However, preliminary basic knowledge of culture and general customs is a good starting point. 104 articulates this as follows;

Cultural awareness cannot be developed in the short space of pre-deployment training and it certainly can't be developed in a classroom environment. An individual's cultural awareness is developed through their own interactions with other cultures.

None of those interviewed had received any form of negotiation training, despite the fact that it was highlighted as an essential skill for CIMIC staff by most interviewees. $\mathrm{IO} 2$ described the frequency of negotiation and said "this [negotiation] is in essence what CIMIC work involves". Fisher \& Ury (1981) describe the frequency of negotiations in everyday interactions, both formal and informal. Formal negotiation training was rated beneficial or extremely beneficial by all participants, particularly wherever a cross-over between culture and negotiation is likely. IO1 describes the interaction between the CIMIC team and the local leaders;

The locals must be sick of seeing us rotating. It can sometimes be a case of "what can you do for me?" So, some form of negotiations training and an awareness of what type of interaction you are likely to encounter would be useful.

Drake (2001) examines the link between culture and negotiation and explains how international negotiators can be influenced by their own cultural values. This cross-over between culture and negotiation is commonplace for CIMIC operators in Lebanon. Having a working knowledge of distributive and integrative bargaining, as detailed by many authors (Drake, 2001; Thompson, 2012; Thompson et al, 1996), forms the basis of most interactions between the CIMIC team and village leaders, as described by 104;

Negotiation training would be beneficial for any member of a CIMIC cell. Knowledge of distributive and integrative bargaining would be beneficial for any CIMIC team member attempting to achieve a positive outcome with a village Mayor. 
Adopting a formalised approach to negotiation training for selected personnel would be beneficial to the DF, not alone for CIMIC appointments but for any appointment holders that are required to interact with the local population. The benefits of negotiation training at all levels across the DF is an area that warrants further examination to determine what is currently offered and the perceived benefits of a structured approach to training of this type.

All interviewees, both Finnish and Irish, agreed that they would now be in a much stronger position to fulfil a CIMIC role than they were pre-deployment. The value of experience and on-the-job learning was highlighted repeatedly throughout the course of the interviews. FO2 described her own experience of learning from the role;

I gained experience about what and how CIMIC is conducted and how it links up with the rest of the unit. Also, to know dos and don'ts in CIMIC. Now I might have different kind of approach to certain things like CIMIC projects and how they are done and what could be useful CIMIC activities to do.

Furthermore, those interviewed expressed a greater understanding and appreciation of the role of the CIMIC team and how it impacts on the rest of the Battalion. 104 explains;

I am currently on my second overseas deployment in UNIFIL, in a different role. I can now appreciate the role of the CIMIC team, this time viewed from a different lens.

\section{Implications for this research}

This research set out to determine if the DF is developing the necessary capability to meet the operational requirements of its UN CIMIC roles. During the course of interviews, it was evident that the DF is meeting the operational requirements of its UN CIMIC roles. However, it is further evident that it is the approach taken by individual DF personnel, rather than their selection and training, that is the main influential factor in the DF meeting these requirements. Irish soldiers are renowned for their empathetic approach to peace-keeping and their ability to "balance a distinctive geopolitical perspective based on their own postcolonial experience" (Sakr, 2013:33). Irish soldiers are also widely "accepted by all sides as impartial brokers without any political agenda" (Sakr, 2013:33). Therefore, the approach taken by Irish troops towards important elements like cultural awareness, negotiations and communicating in Arabic, in a very basic way, all add to the overall acceptance of Irish soldiers in the Middle East. The fact that there is little or no formalised approach to training Irish soldiers in these skills specifically does not significantly impact on the soldiers' ability to carry out their assigned roles effectively. Nevertheless, a formalised approach to training in cultural awareness, negotiations and language skills would certainly benefit the organisation and the individual and may increase the effectiveness of the tactical CIMIC team. 
This section has presented and analysed the findings of the primary research conducted, which was shaped by the research themes revealed through the literature review. As a starting point to answer the research question, it was necessary to look at how the DF selects and trains the personnel selected to fill CIMIC appointments overseas. The literature reviewed highlights the importance of selecting the right people for the right job in the first instance and looks at the processes utilised in the DF in this regard. From this point, an analysis of training specifically focused on CIMIC personnel determined if the right training is being conducted in order to meet the requirements placed on the DF by the UN. From the information provided, some shortfalls were identified in the selection, training and preparation of CIMIC personnel. A number of recommendations have emerged throughout the research and some of these recommendations will feed into areas that warrant further research.

\section{PART FOUR. Conclusions and recommendations}

The literature reviewed identified the findings of Holmes-Eber, Tarzi \& Maki (2016), who posit how an individual's background will have an influence on how they act or react in the future and focus particularly on the cultural awareness and background of the individual. This has a possible relevance for the overseas selection process used within the DF. This is an area that is overlooked in the Irish DF as the selection criteria for CIMIC roles, as detailed by Carberry (2019), is successful completion of a tactical CIMIC course and the appropriate rank. As cultural diversity becomes more commonplace within Irish society, and by reflection in the Irish DF, perhaps this could be an area for development, with potentially positive effects for the Irish DF on overseas deployments. Furthermore, 50\% of the Irish officers interviewed had not completed a tactical CIMIC course prior to selection as a CIMIC officer. The potential negative outcomes of deploying an officer without any prior knowledge of the appointment $\mathrm{s} / \mathrm{he}$ is deploying to cannot be overlooked here.

Tactical CIMIC training is not included on the syllabus for UNIFIL predeployment training or on the Overseas Qualification Course. The assumption is that all individuals selected to fill CIMIC roles will have completed a tactical CIMIC course overseas or the international CIMIC course in UNTSI. Hajjar's (2010) approach displays a requirement for an extended training period in order to develop a proficiency in the area of training concerned. However, there is no standalone tactical CIMIC course offered in UNTSI. Provision of such courses requires external support from lectures and subject matter experts as the number of staff in UNTSI is very limited and would not allow for any additional courses to be run with the current establishment. Therefore, Irish DF students must travel to an overseas training establishment or complete the full international CIMIC course in UNTSI in order to become qualified for a tactical CIMIC appointment.

During the form-up period of pre-deployment training, a cultural awareness lecture is delivered to all junior and senior leaders of the deploying unit. This lecture is delivered by a Lebanese national, when available. Greene-Sands (2014) posits that 
having an understanding of the operational environment through cultural awareness competencies supports commanders at all levels. One lecture during a busy form-up period is not sufficient to fully understand a new culture or to develop competencies to assist in dealing with new cultural norms during deployment.

Although every interaction between the tactical CIMIC team and any of the local key leaders is essentially a negotiation, there is no formal negotiation training available to CIMIC team members before or during deployment. Some of the officers interviewed in this research were able to draw on past personal experiences in procurement or contract negotiations but were not formally prepared to deal with the myriad interactions with local leaders they would have during deployment.

Irish soldiers have been operating in Lebanon for over sixty years. However, there is no formal structure available for soldiers to learn Arabic pre-deployment. The availability of language assistants is limited in UNIFIL and when they are made available, the CIMIC team must rely on what they recount to them after an interaction. There is no way of vetting the information received from them which is often recorded directly in the CIMIC team leader's report. This information can influence the direction and tempo of operations for the tactical component of the deployed unit and indeed the mission.

Many, if not all, of the conclusions identified in this paper hold relevance for any military force deploying to any international military mission regardless of the type of operation the deployed force is engaged in. A strong focus on cultural awareness, language proficiency and negotiation training in particular is highlighted repeatedly throughout recent literature. Providing this training to soldiers of all ranks to a recognised level of proficiency pre-deployment can have an immediate positive impact on the conduct of operations, how the force is received and indeed the general perception of the local population towards the deployed military force.

\section{Recommendations}

In light of the above, the following recommendations are proposed.

- Consideration of an individual's background, using suitability for the role as a sub-criterion for selection, should be introduced into the selection process for some appointments for overseas deployments.

- CIMIC is not limited to the tactical CIMIC team in theatre but should be a consideration for all personnel deployed overseas. As such, a standalone tactical CIMIC course should be developed and offered in UNTSI at least once per year and as required thereafter. All deploying personnel should be required to complete this course prior to overseas service and at intervals during their careers.

- As an organisation that views overseas service as one of its main areas of focus, dedicated training on 'soft military skills' should be incorporated into overseas training for all ranks, similar to weapons handling and physical 
training. These softer skills should specifically include cultural, negotiation and language training.

- Cultural awareness training should be incorporated into the training syllabus in UNTSI. Training should consist of lectures and role play exercises with people of Arabic heritage to ensure a level of realism is introduced into scenario-based training.

- Every individual that has reason to interact with the local population on an overseas deployment should undergo negotiation training pre-deployment. This training would benefit the individual and the unit as personnel conduct their routine tasks. This training should be outsourced and offered as a professional certification that the individual can build on, on future deployments.

- Arabic language training should be available to all personnel who want to develop their language skills. On every overseas deployment, three individuals should be identified whose main responsibility during deployment is to develop Arabic language proficiency. This should be done in a structured way to ensure the organisation can benefit from these skills.

- The establishment of staff in UNTSI should be increased appropriately with subject matter experts to allow for the regular running of courses specific to overseas requirements, focusing particularly on cultural awareness and CIMIC activities. The current establishment of only three officers is not sufficient to properly administer the running of additional courses.

\section{Areas for further research}

During the course of this research, a number of areas arose which were not within the scope of this paper, but which warrant further research. The measurability of success for any appointment or task within the UN framework is not defined. This makes the question of whether or not a nation has achieved mission success during deployment difficult to define. Perhaps the absence of death or serious incident is enough to warrant a successful outcome from a deployment, but measurable criteria would assist in training and reviews of operations.

Miler (2012) reports how UN CIMIC units help to develop a positive image of soldiers and help establish good relations with local governments and the wider population. De Coning (2007) argues how UN CIMIC has a very important role to play in the context of mission and community support. The UN itself, focuses its CIMIC activities on building positive relationships with the local population (un.org, 2019). In May 2018, Maj Gen Beary opened the third LAF CIMIC centre in Lebanon and stated that the event "marked the achievement of UNIFIL's initial objective of enhancing UNIFIL's CIMIC partnership with LAF" (peacekeeping.un.org, 2018). The Irish tactical CIMIC team feeds into this mechanism in no small way.

There is no doubt therefore that the Irish DF is meeting the operational requirements of its UN CIMIC tasks, but it may be doing so by consequence of its soldiers' collective attitudes and behaviour rather than by design. Sakr (2013) 
describes how the reputation that Ireland has built up in Lebanon over the past sixty years of service in the country is of an extremely high standard, due in no small part to the nature and approach of the individual Irish soldier. The empathetic nature of Irish soldiers and their ability to apply an 'Irish approach' to any and all scenarios they encounter during deployment positively influences the attitude of the local population towards the deployed force. With the correct balance of cultural awareness, empathy and the perception of approachability displayed by Irish soldiers, the intricacies of peace-keeping appear to come naturally to Irish soldiers.

The success Irish soldiers have had as peace-keepers, in the absence of formal training in the softer military skills, is an area of interest and one that certainly warrants further research. Cole (2017:5) details a visit to South Lebanon in 2015 when the Director and staff at the local orphanage in Tibnine village asked "if the UN contingent boundaries could be redrawn, so that their village could once again come within the Irish AO". Interactions and requests of this nature are detailed in several published papers regarding Irish peace-keepers in Lebanon. Further research on what makes the 'Irish approach' to peace-keeping so unique would undoubtedly reveal some interesting results.

Please note that the views expressed in this article are those of the author alone and should not be taken to represent the views of the Irish Defence Forces, the Command and Staff School or any other group or organisation.

\section{References}

Agar, M.H., (1986) Speaking of Ethnography. Sage University Paper series on Qualitative Research Methods, Volume 2. Beverly Hills, CA.

Asch, B.J., Winkler, J.D. (2013), Rand Corporation \& National Defense Research Institute (U.S.), Ensuring language capability in the intelligence community: what factors affect the best mix of military, civilians, and contractors? Santa Monica, CA, USA.

Bloor, M., 2001. Focus groups in social research. Thousand Oaks, CA. Sage.

Bolopion, P., (2006) “UNIFIL's Disarmament Mission”, globalpolicy.org, Aug 2006, available:

https://www.globalpolicy.org/component/content/article/193/38979.html [accessed 18 July 2018]

CIMIC in UN Integrated Peacekeeping Missions Policy, (2010), UN DPKO, Dept of Field Support, un.org, Feb 2010, available:

http://dag.un.org/bitstream/handle/11176/89511/2010.02UNCIMICPolicy.pdf?seq uence=1\&isAllowed $=y$ [accessed 03 Jan 2019]

CIMIC Field Handbook, (2014), Civil-Military Co-Operation Centre of Excellence CCOE, 3rd Edition 2014, available: https://www.cimic-coe.org/wpcontent/uploads/2014/06/CIMIC-Handbook.pdf [accessed 03 Jan 2019] 
Cole, D (2017) "From Galway to the Gaza Strip"- A Critical Analysis of the Perspectives, Motivations and Policy Impact of Ireland's Involvement in UN Peacekeeping Operations in the Middle East, CISD Yearbook of Global Studies Volume 4, p 1-35

Crawford, K.F., Lebovic, J.H. \& Macdonald, J.M. (2015), "Explaining the Variation in Gender Composition of Personnel Contributions to UN Peacekeeping Operations", Armed Forces \& Society, vol. 41, no. 2, pp. 257-281.

Creswell, J. (1998). Qualitative inquiry and research design: Choosing among five traditions. Thousand Oaks, CA: Sage.

De Coning, C., (2005). Civil-military coordination and UN peacebuilding operations. African Journal on Conflict Resolution, 5(2), pp.89-118.

De Coning, C., (2007). Civil-military coordination practices and approaches within United Nations peace operations. Journal of Military and Strategic Studies, 10(1).

Drake, L.E., 2001. The culture-negotiation link. Integrative and distributive bargaining through an intercultural communication lens. Human Communication Research, 27(3), pp.317-349.

Eisner, E., (2001). Qualitative Research. London: Sage Publications.

Erikson, P., (2004). Civil-military Co-ordination in Peace Support Operations--an Impossible Necessity?. Journal of Humanitarian Assistance. Tufts University, MA, USA

Fisher, R., \& Ury, W. (1981), Getting to Yes, Houghton Mifflin, Boston, USA

Gourlay, C., (1999). Partners apart: managing civil-military cooperation in humanitarian interventions. UNIDIR, available:

https://www.peacepalacelibrary.nl/ebooks/files/UNIDIR_pdf-art131.pdf [accessed 18 March 2019]

Hajjar, R. M. (2010). A new angle on the U.S. military's emphasis on developing cross-cultural competence: Connecting in-ranks' cultural diversity to cross-cultural competence. Armed Forces and Society, 36, 247-63.

Hicks, K.H and Wormuth, C.E., (2009). The future of US civil affairs forces. CSIS. Holmes-Eber, P., Tarzi, E. and Maki, B. (2016) 'U.S. Marines' Attitudes Regarding Cross-Cultural Capabilities in Military Operations: A Research Note', Armed Forces \& Society, 42(4), pp. 741-751.

Holshek, C., (2013), 'United Nations Civil-Military Coordination (UN-CIMIC)', Peace Operations Training Institute, available:

https://www.peaceopstraining.org/blog/252/united-nations-civil-militarycoordination-un-cimic/ [accessed 17 July 2018] 
Irish Defence Forces (2018), Current overseas missions, military.ie, available: http://www.military.ie/overseas/current-missions/unifil/ [accessed 12 Dec 2018]

Irish Times (2018), Over 100 additional soldiers to join UNIFIL in Lebanon, irishtimes.com, available: https://www.irishtimes.com/news/politics/over-100additional-irish-soldiers-to-join-unifil-in-lebanon-1.3618484 [accessed 12 Dec 2018] Jenkins, L., (2003). A CIMIC contribution to assessing progress in peace support operations. International Peacekeeping, 10(3), pp.121-136.

Karim, S. and Beardsley, K., (2013). Female peacekeepers and gender balancing: token gestures or informed policymaking? International Interactions, 39(4), pp.461488.

Lofland, J. (1971) Analysing Social Settings: A Guide to Qualitative Observation and Analysis, California: Wadsworth.

Longhurst, G.M., (2007). The evolution of Canadian civil-military cooperation (CIMIC). Canadian Military Journal, Winter 2006-2007, pp.55-64.

Longhurst, R., (2003). Semi-structured interviews and focus groups. Key methods in geography, pp.117-143, Thousand Oaks, CA

Marta, L, (2009), "The UNIFIL II mission in Lebanon: Italy's contribution (ARI)", realinstitutoelcano.org, Sep 2009, available:

http://www.realinstitutoelcano.org/wps/portal/rielcano en/contenido?WCM_GLO BAL CONTEXT=/elcano/elcano in/zonas in/defense+security/ari125-2009

[accessed 18 July 2018]

Miler, A. (2012), "Scientific Quarterly No. 4(89)", National Defence University, 2012, Warsaw, available:

http://wydawnictwo.aon.edu.pl/en/images/zeszyty/archiwum/ZN4 2012 en.pdf\#p age $=277$ [accessed 19 July 2018]

Miles, D. (2006), "American Forces Press Service : "jointness" becomes key focus in developing military capability", Defense AT \& L, vol. 35, no. 4, pp. 56.

NATO CCOE, (2018), NATO, available: https://www.cimic-coe.org/ [accessed 17 July 2018]

Office of the Under Secretary of Defense, Personnel \& Readiness. (2016).

Population representation in the military services: Fiscal year 2015. Appendix D:

Historical data. Table D-10, cna.org 2015, available: https://www.cna.org/poprep/2015/contents/contents.html [accessed 02 Jan 2019]

Otwinowska-Kasztelanic, A., (2011). Do we need to teach culture and how much culture do we need?. In Aspects of culture in second language acquisition and foreign language learning (pp. 35-48). Springer, Berlin, Heidelberg.

Rehse, P., (2005). CIMIC: Concepts, definitions and practice. Hamburg, Germany 
Reyskens, P. \& Resteigne, D. (2015), "Between practicing and rehearsing. Cultural awareness challenges in the military", European journal for Research on the Education and Learning of Adults, vol. 6, no. 2, pp. 211;-225

Sabrosky, A.N. and Sloane, R.L., (1989). The Recourse to War: An Appraisal of the 'Weinberger Doctrine'. Army War College strategic studies inst, Carlisle Barracks, PA.

Sakr, R., (2013). "UN in the Arab World. Irish Peacekeeping in the United Nations Interim Force in Lebanon, A Historical, Political and Socio-Cultural Study" American University of Beirut, Lebanon

Sands, R.G. \& Greene-Sands, A. (2014), Cross-cultural competence for a twentyfirst-century military: culture, the flipside of COIN, Lexington Books, Lanham, MD.

Schommer-Atkins, M. (2002) 'An evolving theoretical framework for an epistemological belief system', in Hofer, B. and Pintrich, P. (eds.), Personal Epistemology: The Psychology of Beliefs About Knowledge and Knowing, London: Routledge.

Selmeski, B.R., (2007). Military cross-cultural competence: Core concepts and individual development. Centre for Security, Armed Forces \& Society, Royal Military College of Canada.

Sepp, K.I. 2(007), "From 'shock and awe' to 'hearts and minds': the fall and rise of US counterinsurgency capability in Iraq", Third World Quarterly, vol. 28, no. 2, pp. 217-230.

Shea, T.C., (2005). Transforming military diplomacy. George C Marshall Centre APO AE 09053, European Centre for Security Studies.

Silverman, D. (2000) 'Analysing Talk and Text', in Denzin, N.K. and Lincoln, Y.S. Handbook of Qualitative Research, (2nd edition), Thousand Oaks, CA.

Slim, H, (1996), The Stretcher and the Drum: Civil-Military Relations in Peace Support Operations, International Peacekeeping, vol. 3, no. 2, p. 124.

Strauss AL, Corbin J. (1998), Basics of qualitative research: grounded theory procedures and techniques, Sage Publications, Thousand Oaks, CA

Sutton, J. \& Austin, Z. (2015), "Qualitative research: Data collection, analysis, and management", Canadian Journal of Hospital Pharmacy, vol. 68, no. 3, pp. 226-231

Thompson, L., Peterson, E. and Brodt, S.E., 1996. Team negotiation: An examination of integrative and distributive bargaining. Journal of Personality and Social Psychology, 70(1), p.66.

Thompson, L.L., (2012). The mind and heart of the negotiator 5th Ed., Prentice Hall, NJ, USA 
Thynne, K. and Cherne, G., (2016). Preparation starts at home: Education and training for civil-military interaction. In Effective civil-military interaction in peace operations (pp. 61-75). Springer, Cham.

Toonen, W., (2017), 'CIMIC In Missions and Operations, Reflections on History, Current Affairs and Perspectives' CCOE, The Hague.

UN DPKO, (2002). "Civil-Military Coordination Policy", Department of Peacekeeping Operations (DPKO), New York, USA

United Nations, (2018), "New LAF CIMIC Centre in South Lebanon to better serve communities", peacekeeping.un.org, 18 May 2018, available:

https://peacekeeping.un.org/en/new-laf-cimic-centre-south-lebanon-to-betterserve-communities [accessed 18 July 2018].

United Nations, (2018), UNIFIL, available:

https://peacekeeping.un.org/en/mission/unifil [accessed 18 July 2018]

United Nations, (2018), UNIFIL, available: https://unifil.unmissions.org/faqs [accessed 18 July 2018]

United Nations, (2018), UNIFIL, available: https://unifil.unmissions.org/unifilmandate [accessed 19 July 2018]

Verkuyten, M. and Slooter, L., 2008. Muslim and non-Muslim adolescents' reasoning about freedom of speech and minority rights. Child Development, 79(3), pp.514-528.

Watkins S. J., Sherk J. (2008). Who serves in the U.S. military? Demographic characteristics of enlisted troops and officers, heritage.org, 21 Aug 2008, available: http://www.heritage.org/research/reports/2008/08/who-serves-in-the-us-militarythe-demographics-of-enlisted-troops-and-officers [accessed 02 Jan 2019]

Weinberger doctrine 2001, 1st edition, Oxford University Press, UK.

Whalan, J., 2017. Dealing with Disgrace: Addressing Sexual Exploitation and Abuse in UN Peacekeeping. Providing for Peacekeepers, Queensland.

Wolcott, H. (2001) Writing up Qualitative Research (2nd edn.), Thousand Oaks, CA. 